\title{
TP53INP2 Promotes Bovine Adipocytes Differentiation Through Autophagy Activation
}

\author{
Weiyi Zhang ${ }^{1}{ }^{10}$, Peiwei Li ${ }^{1}$, Shijie Wang ${ }^{1}$, Gong Cheng ${ }^{1}$, Li Wang ${ }^{1}$, Xue $\mathrm{Mi}^{1}{ }^{1}$, Xiaotong Su ${ }^{1}$, \\ Yaning Wang ${ }^{1}$ and Linsen Zan ${ }^{1,2, *}$ \\ 1 College of Animal Science and Technology, Northwest A\&F University, Yangling 712100, Shaanxi, China; \\ zhangweiyi-@outlook.com (W.Z.); lipeiwei@nwafu.edu.cn (P.L.); 2017050483@nwafu.edu.cn (S.W.); \\ chenggong@nwafu.edu.cn (G.C.); lw@nwafu.edu.cn (L.W.); rsmx@nwafu.edu.cn (X.M.); \\ xiaotongsu@gmail.com (X.S.); wangyn1992@outlook.com (Y.W.) \\ 2 National Beef Cattle Improvement Center in China, Yangling 712100, Shaanxi, China \\ * Correspondence: zanlinsen@163.com
}

Received: 11 October 2019; Accepted: 27 November 2019; Published: 2 December 2019

check for updates

Simple Summary: In this article explore the role of the bovine TP53INP2 gene in adipocyte differentiation and its function in autophagy during the early stage of adipocyte differentiation. In our work we found that a novel, important autophagy related protein TP53INP2 can activate autophagy during the early stage of differentiation in bovine adipocytes and positively regulate adipocyte differentiation by affecting autophagy. Furthermore, we demonstrated that peroxisome proliferator-activated receptor gamma (PPAR $\gamma$ ) also contributed to the function of TP53INP2 in modulating adipocyte differentiation. The study of the function of bovine TP53INP2 gene on adipocyte differentiation has not been reported, therefore, we have decided to focus on Qinchuan cattle, one of the five important cattle breeds in China. We propose that the TP53INP2 gene may affect the meat quality of Qinchuan cattle by regulating lipid deposition, and may shed new light on the developmental mechanisms of adipose development.

\begin{abstract}
Tumor protein p53 inducible nuclear protein 2 (TP53INP2) is a key positive regulator of autophagy, and it has been shown to modulate adipocyte differentiation. However, the molecular mechanism involved in autophagy regulation during adipocyte differentiation has not been clarified. Our experiments were intended to investigate whether TP53INP2 is involved in the regulation of autophagy during bovine adipocyte differentiation and how TP53INP2 affects the differentiation of bovine adipocytes. In our research, using RT-qPCR and Western blot methods, we found that the overexpression of TP53INP2 resulted in the upregulation of adipogenesis and autophagy-related genes, and autophagy flux and the degree of differentiation were detected by LipidTOX ${ }^{\mathrm{TM}}$ Deep Red Neutral Lipid staining and dansylcadaverine staining, respectively. The knockdown of TP53INP2 produced results that were the inverse of those produced by the overexpression of TP53INP2. Overall, our results suggested that TP53INP2 can activate autophagy during the early stage of differentiation in bovine adipocytes and positively regulate adipocyte differentiation by affecting autophagy. Additionally, peroxisome proliferator-activated receptor gamma (PPAR $\gamma$ ) also contributed to the function of TP53INP2 in modulating adipocyte differentiation.
\end{abstract}

Keywords: TP53INP2; autophagy; adipocyte differentiation; lipid droplets; PPAR $\gamma$

\section{Introduction}

Autophagy is a lysosomal degradation pathway [1] that can remove excess or damaged organelles or macromolecules to maintain the recycling of intracellular substances [1-3] and the homeostasis 
of the internal environment [4]. Autophagy also plays an important role in some diseases [5]. It is initiated in a double-membrane structure called the autophagosome after membrane expansion. Then, the whole membrane encloses the contents. Finally, autophagosomes will move toward and fuse with lysosomes and assemble into autolysosomes that contain hydrolases that can degrade substances [6,7]. Many studies have confirmed that autophagy is involved in the differentiation of adipocytes and plays an essential role in the early stage of differentiation [8-10]. Inhibiting autophagy during the process of preadipocyte differentiation into mature adipocytes blocks normal differentiation. The characteristics of brown adipocytes appear in white adipocytes when autophagy is blocked in adipocyte differentiation; lipid droplets become smaller, the number of mitochondria increases, the $\beta$-oxidation rate and insulin sensitivity increase, and the lipid content is reduced [11,12]. The tissue-specific knockout of the autophagy-related gene ATG5 in mice will affect adipogenesis and lipid accumulation [13]. ATG7 encodes an E1-like activating enzyme that is necessary for autophagy. A previous study revealed that ATG7 could regulate adipocyte differentiation in mice [14].

Tumor protein p53 inducible nuclear protein 2 (TP53INP2), also known as DOR or PINH, is a dual regulator of transcription and autophagy. The tumor protein p53 inducible nuclear protein family has two members, TP53INP1 and TP53INP2. Extensive research has been conducted on TP53INP1, which is involved in the cell stress response, inhibits cell proliferation and promotes apoptosis. TP53INP2 is a vital paralog of TP53INP1, which is a positive regulator of autophagy. However, there has been less research on TP53INP2. Existing reports have shown that TP53INP2 can interact physically with some important autophagy-related genes, such as MAP1LC3A, GABARAP and GABARAPL2, and it can recruit them to autophagosome membranes and link them to VMP1. All of the autophagy-related genes mentioned above play pivotal roles in autophagosome development. Recently, TP53INP2 has been found to play a novel role in death-receptor signaling, and it can positively regulate apoptosis [15-17]. The latest results have reported that TP53INP2 could negatively regulate adipogenesis in human and mouse preadipocytes [18].

Adipose tissue is a vital endocrine organ that maintains energy homeostasis and is critical for mammalian development [19-21]. It has been demonstrated that adipose tissue could regulate nutritional metabolism and lipid storage [22,23]. Adipogenesis is a complex process, and differentiation is a critical process, after which adipocytes are occupied by large lipid droplets rich in TG [24,25]. Many studies have reported that several important transcription factors, such as peroxisome proliferator-activated receptors (PPAR $\gamma)$, CCAAT/enhancer-binding protein alpha $(\mathrm{CEBP} \alpha)$, and fatty acid-binding protein (FABP4) regulate differentiation [26-28]. In addition to investigating these regulators, it is also necessary to study the mechanisms of the regulation of differentiation involving other novel genes.

To date, there have been few reports on autophagy regulating the differentiation of bovine adipocytes, and the study of the bovine TP53INP2 gene has not been reported. Therefore, we have decided to focus on Qinchuan cattle, one of the five important cattle breeds in China. We propose that the TP53INP2 gene may affect the meat quality of Qinchuan cattle. Therefore, we explored the role of the bovine TP53INP2 gene in adipocyte differentiation and its function in autophagy during the early stage of adipocyte differentiation. Ultimately, our experiments found that PPAR $\gamma$ and autophagy contributed to the function of TP53INP2 in bovine adipocyte differentiation. Therefore, we suggest that TP53INP2 is the key regulator of differentiation in bovine adipocytes.

\section{Materials and Methods}

Bovine pre-adipocytes were isolated from a one-day-old healthy calf born at the experimental base of the National Beef Cattle Improvement Center (Yangling, China). The care and feeding of the animals used in this study were approved by the Institutional Animal Care and Use Committee of China (College of Animal Science and Technology, Northwest A\&F University, China; No. 2013-23, 20 April 2013). The implementation of the animal experimental procedures was performed in strict 
accordance with the guidelines of the Administration of Affairs Concerning Experimental Animals (Ministry of Science and Technology, China, 2004).

\subsection{Isolation of Bovine Adipocytes}

Subcutaneous adipose tissue was harvested under sterile conditions and placed in 1x PBS (Gibco, Grand Island, NY, USA) with 10\% penicillin/streptomycin (Gibco). It was then immediately taken out. Under a stereo-dissecting microscope, the subcutaneous adipose tissues were dissected away from the connective tissue and blood vessels with sterile forceps and scissors. The adipose tissue was cut into small pieces. The minced tissue blocks were digested with $0.25 \%$ collagenase I (Sigma, Kawasaki City, Japan) and $0.1 \%$ dispase II (Roche, Basel, Switzerland) for $1-2 \mathrm{~h}$ at $37^{\circ} \mathrm{C}$ in a water bath. The digested mixture was filtered through an $80-\mu \mathrm{m}$ cell strainer and centrifuged at $1500 \mathrm{~g}$ for $10 \mathrm{~min}$, and the supernatant was discarded. The cells were resuspended in complete growth medium (Dulbecco's modified Eagle medium/F-12 (DMEM/F-12), Gibco) with 15\% fetal bovine serum (Gibco) and $1 \%$ penicillin/streptomycin) and seeded in $60 \mathrm{~mm}$ Petri dishes, and the medium was changed every two days.

\subsection{Cell Culture and Transfection}

Bovine pre-adipocytes were cultured in DMEM/F-12 with 15\% fetal bovine serum (Gibco) and $1 \%$ penicillin and streptomycin at $5 \% \mathrm{CO}_{2}$ and $37^{\circ} \mathrm{C}$. Adipocyte differentiation was induced by an induction medium containing DMEM/F-12 with $15 \%$ FBS, $1 \%$ penicillin and streptomycin, $0.50 \mathrm{mM}$ isobutylmethylxanthine (IBMX, Sigma, Kawasaki City, Japan), 1 mM Dexamethasone (Dex, Sigma, Saint Louis, MO, USA), and $1 \mathrm{mg} / \mathrm{mL}$ insulin. The first and second days of treatment with the induced differentiation medium were referred to as D0 and D1. Then, the maintenance medium (DMEM/F-12 with $15 \% \mathrm{FBS}, 1 \%$ penicillin and $1 \mathrm{mg} / \mathrm{mL}$ insulin) was changed every other day until the fifth day. The cells were transfected when the density reached approximately $70 \%$ and were starved for two hours in serum-free OptiMEM (Gibco) before transfection. The CDS sequence of TP53INP2 cDNA was subcloned into the pcDNA3.1(+) vector, which was used to overexpress TP53INP2, and was transfected, along with pcDNA3.1(+) empty vector, siRNA $(20 \mu \mathrm{M})$, and NC (negative control, $20 \mu \mathrm{M}$ ) (Ribobio, Guangzhou, China) into cells with the FuGENE ${ }^{\circledR}$ HD transfection reagent according to the transfection protocol. Rosiglitazone $(2 \mu \mathrm{M})$ was used to increase the expression level of PPAR $\gamma$.

\subsection{Quantitative RT-PCR}

Total cellular RNA was extracted with RNAiso Plus (Takara, Mountain View, CA, USA) reagent according to the manufacturer's instructions. cDNA synthesis was performed using an RT reagent kit with gDNA Eraser (Takara) according to general experimental procedures. The relative expression of mRNA was determined by quantitative RT-PCR using the TB Green Premix Ex Ta II kit (Takara). The results of RT-PCR were calculated by using the $2^{-\Delta \Delta C t}$ method [29]. $\beta$-actin was used to normalize all genes expression levels. All primers were synthesized by TSINGKE Biological Technology Co. (Xi'an, Shanxi, China), and the sequence information is listed in Table 1.

\subsection{Western Blot}

Total cellular protein was isolated from adipocytes with a protein extraction kit (Solarbio Company, Beijing, China) after mixing with protein loading buffer and denaturation for $10 \mathrm{~min}$ in a $100{ }^{\circ} \mathrm{C}$ metal bath. A $20-\mu \mathrm{g}$ protein sample was electrophoresed on a $12 \%$ gel, and the protein was transferred to a PVDF membrane after gel electrophoresis. Next, the membrane was incubated with antibodies against $\beta$-ACTIN (1:5000, NOVUS, HK, NP_776404.2), TP53INP2 (1:2000, AVIVA Systems Biology, San Diego, CA, USA, XP_003586891.1), PPAR $\gamma$ (1:1000, Boster, Wuhan, China, NP_851367.1), PLIN2 (1:2000, Abcam, Cambridge, UK, NP_776405.1), FASN (1:2000, Abcam, NP_777087.1), p62 (1:2000, Abcam, NP_788814.1), or LC3 (1:2000, Abcam, NP_001001169.1) for $12 \mathrm{~h}$ at $4{ }^{\circ} \mathrm{C}$. After washing the membrane three times (10 min each) with PBS-Tween 20 , the membrane was incubated with the 
secondary antibody for $1 \mathrm{~h}$ and then washed three times with PBS-Tween 20 (10 min each). Finally, equal amounts of luminol reagent and peroxide solution were mixed in an EP tube and added dropwise to the PVDF membrane. The Gel Doc ${ }^{\mathrm{TM}}$ XR+ Gel Documentation System (Bio-Rad, Hercules, CA, USA) was used to detect the immunoreactivity.

Table 1. List of the sequences of all primers, GenBank accession numbers and the size of the product in this study.

\begin{tabular}{|c|c|c|c|c|}
\hline Gene & Primer & Sequence & $\begin{array}{c}\text { Genebank } \\
\text { Accession No }\end{array}$ & Product Size(bp) \\
\hline \multirow{2}{*}{ TP53INP2 } & F & GCGGCTGTAGACTCAAAG & \multirow{2}{*}{ XM_003586843.5 } & \multirow{2}{*}{130} \\
\hline & $\mathrm{R}$ & GTTATGAGGCGGAGTGTC & & \\
\hline \multirow{2}{*}{$P P A R \gamma$} & F & GTTATGAGGCGGAGTGTC & \multirow{2}{*}{ NM_181024.2 } & \multirow{2}{*}{117} \\
\hline & $\mathrm{R}$ & GTCCTCCGGAAGAAACCCTTG & & \\
\hline \multirow{2}{*}{ PLIN2 } & $\mathrm{F}$ & TGTCTACCAAGCTCTGCTC & \multirow{2}{*}{ NM_173980.2 } & \multirow{2}{*}{210} \\
\hline & $\mathrm{R}$ & CGATGCTTCTCTTCСАСТСС & & \\
\hline \multirow{2}{*}{ FASN } & $\mathrm{F}$ & GATCСТССТСАТСССАATAGTTC & \multirow{2}{*}{ NM_174662.2 } & \multirow{2}{*}{117} \\
\hline & $\mathrm{R}$ & TTCAGTTGCCTCCCTTCATC & & \\
\hline \multirow{2}{*}{ ATG7 } & F & GCCAAAACAGATTCAAGCCCTCG & \multirow{2}{*}{ NM_001142967.1 } & \multirow{2}{*}{109} \\
\hline & $\mathrm{R}$ & CAGCACCGTGGTCTCGTCATACTT & & \\
\hline \multirow{2}{*}{$B E C N 1$} & F & GATGTCCACAGAAAGTGCCAACA & \multirow{2}{*}{ NM_001033627.2 } & \multirow{2}{*}{100} \\
\hline & $\mathrm{R}$ & GTCCCCAGTGACCTTTAGTCTTCG & & \\
\hline \multirow{2}{*}{$\beta$-Actin } & F & TCTAGGCGGACTGTTAGC & \multirow{2}{*}{ NM_173979.3 } & \multirow{2}{*}{82} \\
\hline & $\mathrm{R}$ & CCATGCCAATCTCATCTCG & & \\
\hline
\end{tabular}

\subsection{Dansylcadaverine Staining and Lipid Droplet Staining}

Dansylcadaverine, a fluorescent stain, is commonly used to monitor autophagy vacuoles. Adipocyte lipid droplet staining was performed with HCS LipidTOX ${ }^{\mathrm{TM}}$ Deep Red Neutral Lipid Stain (Thermo Fisher, Waltham, MA, USA). After washing cells with PBS three times, the adipocytes were fixed with $4 \%$ formaldehyde and incubated for $30 \mathrm{~min}$ at room temperature. Next, the formaldehyde was removed, and the cells were gently washed with PBS three times, after which $0.5 \mathrm{mM}$ dansylcadaverine stain (Sigma) was added ( $1 \mathrm{uL}$ per well in a 6-well plate) and incubated at $37^{\circ} \mathrm{C}$ for $40 \mathrm{~min}$. After that, the dansylcadaverine stain was removed, and the cells were washed with PBS 3 times. LipidTOX ${ }^{\mathrm{TM}}$ neutral lipid stain was added ( $1 \mathrm{uL}$ per well in a 6-well plate), and the cells were incubated at room temperature for $30 \mathrm{~min}$. Finally, the LipidTOX ${ }^{\mathrm{TM}}$ stain was removed, and the cells were washed three times with PBS. Then, DAPI stain (Sigma) was added (1 uL per well in a 6-well plate) and incubated at room temperature for 10 min before cell imaging.

\subsection{Statistical Analysis}

All data in this study are represented as the mean \pm SEM and were analyzed with GraphPad Prism 5.0 (software Inc., San Diego, CA, USA). The significance of the differences between groups was calculated by a $t$-test or ANOVA $\left(*, p<0.05 ;{ }^{* *}, p<0.01\right)$.

\section{Results}

\subsection{Constructing and Transfecting pcDNA3.1(+)-TP53INP2 to Overexpress TP53INP2 and Transfecting} Si-TP53INP2 to Interfere with TP53INP2

The complete CDS sequence of the bovine TP53INP2 gene was subcloned into the pcDNA3.1(+) vector. When the cell density reached $70 \%$, the overexpression vector was transfected into adipocytes. At $48 \mathrm{~h}$ after transfection, we tested the overexpression efficiency of TP53INP2, and the mRNA level of TP53INP2 was upregulated nearly 500-fold compared to that in the negative control cells (Figure 1a). The TP53INP2 protein level was also significantly increased (Figure 1b, Supplemental Figure S1a). In addition, we synthesized and transfected three small interfering RNAs targeting the bovine TP53INP2 
gene. Similarly, the interference efficiency was assessed at $48 \mathrm{~h}$ after transfection, and the siRNA with the highest interference efficiency was selected. RT-qPCR analysis showed that the mRNA expression of TP53INP2 was decreased nearly $80 \%$ compared to that in the NC (Figure 1c). Western blot analysis showed that the protein level was also significantly decreased (Figure 1d, Supplementary Materials, Figure S1b). In addition, we also detected overexpression and interference efficiency of mRNA levels at $24 \mathrm{~h}, 72 \mathrm{~h}$ and $150 \mathrm{~h}$ after transfection (Supplementary Materials, Figure S2a-h).

(a)

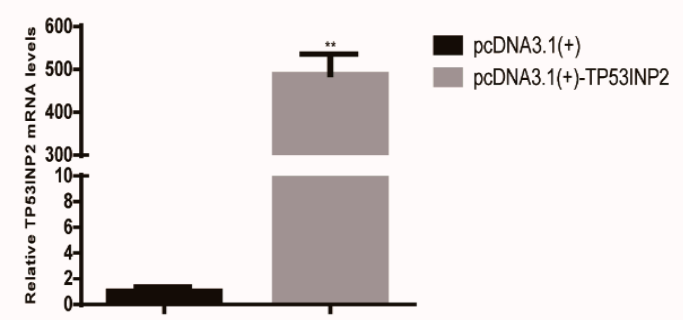

(c)

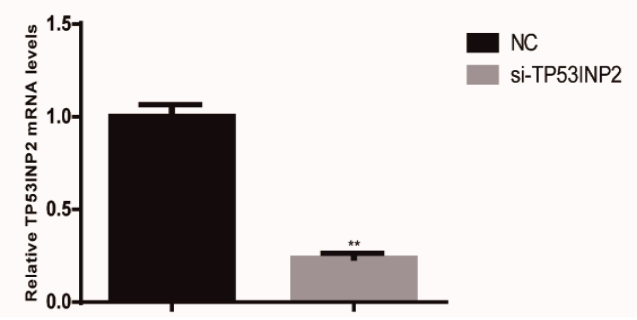

(b)

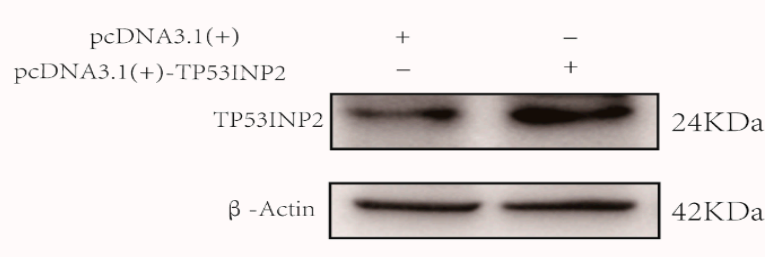

(d)

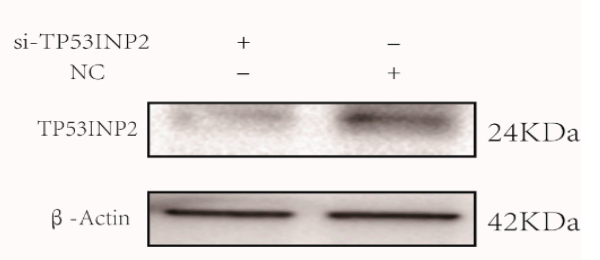

Figure 1. Detection of overexpressing and interference efficiency. (a) The mRNA and (b) protein levels of overexpressing efficiency after transfection for $48 \mathrm{~h}$ were nearly 500 -fold and 2 -fold, respectively. (c) The mRNA and (d) protein levels of interfering efficiency after transfecting for $48 \mathrm{~h}$ were nearly $80 \%$. Bar graphs are expressed as mean \pm S. E.M. $(n=3),{ }^{* *}, p<0.01$, compared with NC and empty vector. NC, negative control.

\subsection{TP53INP2 Promotes Differentiation in Bovine Adipocytes}

We first determined the mRNA expression of TP53INP2 during differentiation (Figure 2a). To explore the role of TP53INP2 in adipocyte differentiation and adipogenesis, we transfected adipocytes with siRNA (small interfering RNA) and NC or NC alone as a control. Our results showed that the mRNA and protein levels of PPAR $\gamma$ and perilipin-2 (PLIN2) gradually increased during differentiation, while the level of fatty acid synthase (FASN) increased first and then decreased. The knockdown results showed that both the mRNA and protein expression of the differentiation marker PPAR $\gamma$ and the adipogenesis markers PLIN2 and FASN were significantly decreased by knocking down TP53INP2 during differentiation (Figure 2b-e, Supplementary Materials, Figure S3a-c). In addition, LipidTOX ${ }^{\text {тм }}$ Deep Red Neutral Lipid Stain showed that the lipid droplets in cells in the si-TP53INP2 group were clearly less than those in the control group (Figure 3a, Supplementary Materials, Figure S5a). To further explore the function of TP53INP2 in adipocytes, we also transfected a pcDNA3.1(+)-TP53INP2 plasmid to overexpress TP53INP2 and an empty vector as a negative control. The overexpression results showed inverse trends; both the mRNA and the protein expression of the differentiation marker PPAR $\gamma$ and the adipogenesis markers PLIN2 and FASN were significantly increased during differentiation (Figure 2f-i, Supplementary Materials, Figure S3d-f). Consistent with this, the overexpression of TP53INP2 increased the lipid droplet content (Figure 3b, Supplementary Materials, Figure S5b). In general, our experimental results showed that TP53INP2 promoted bovine adipocyte differentiation. 

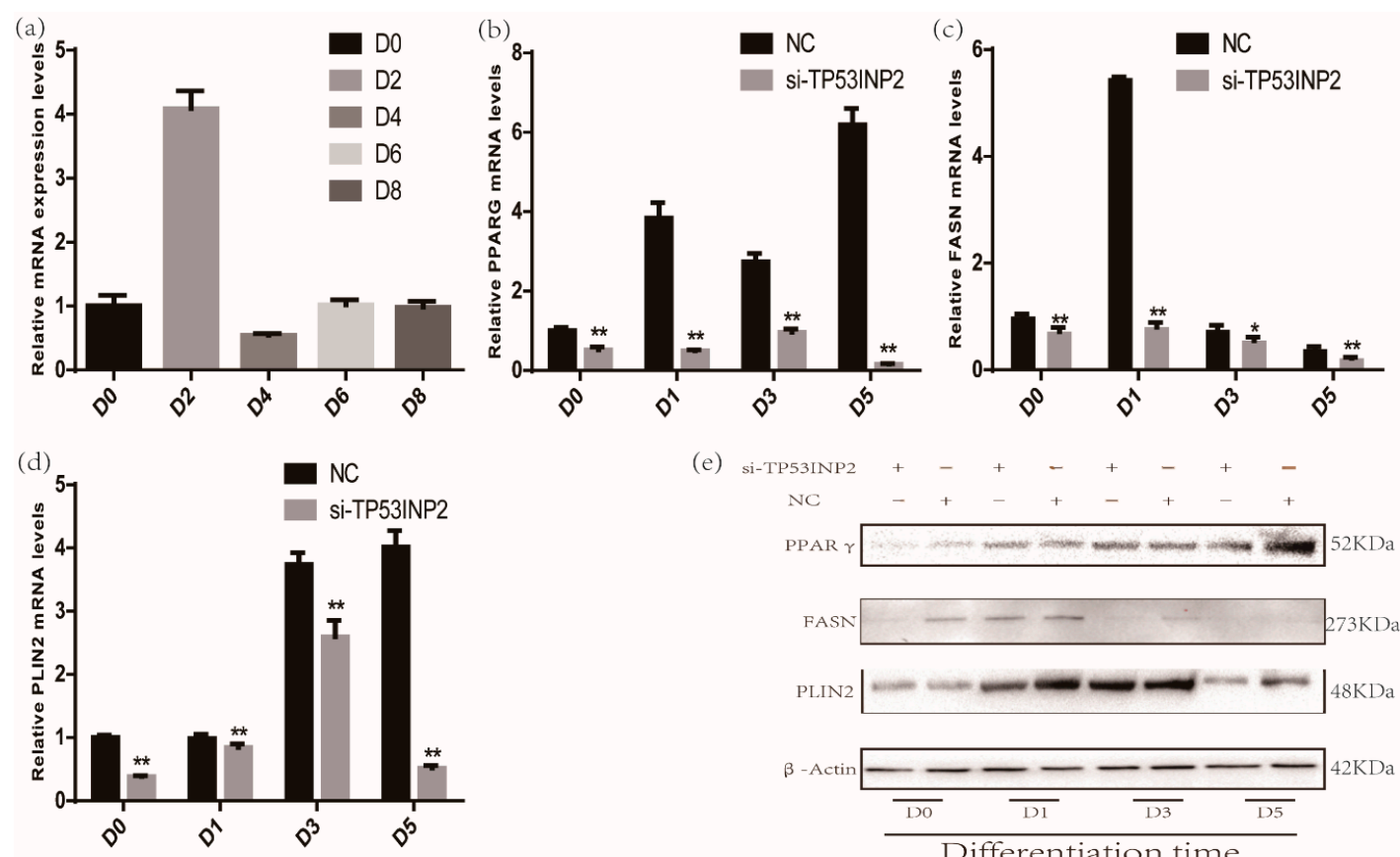

(e)
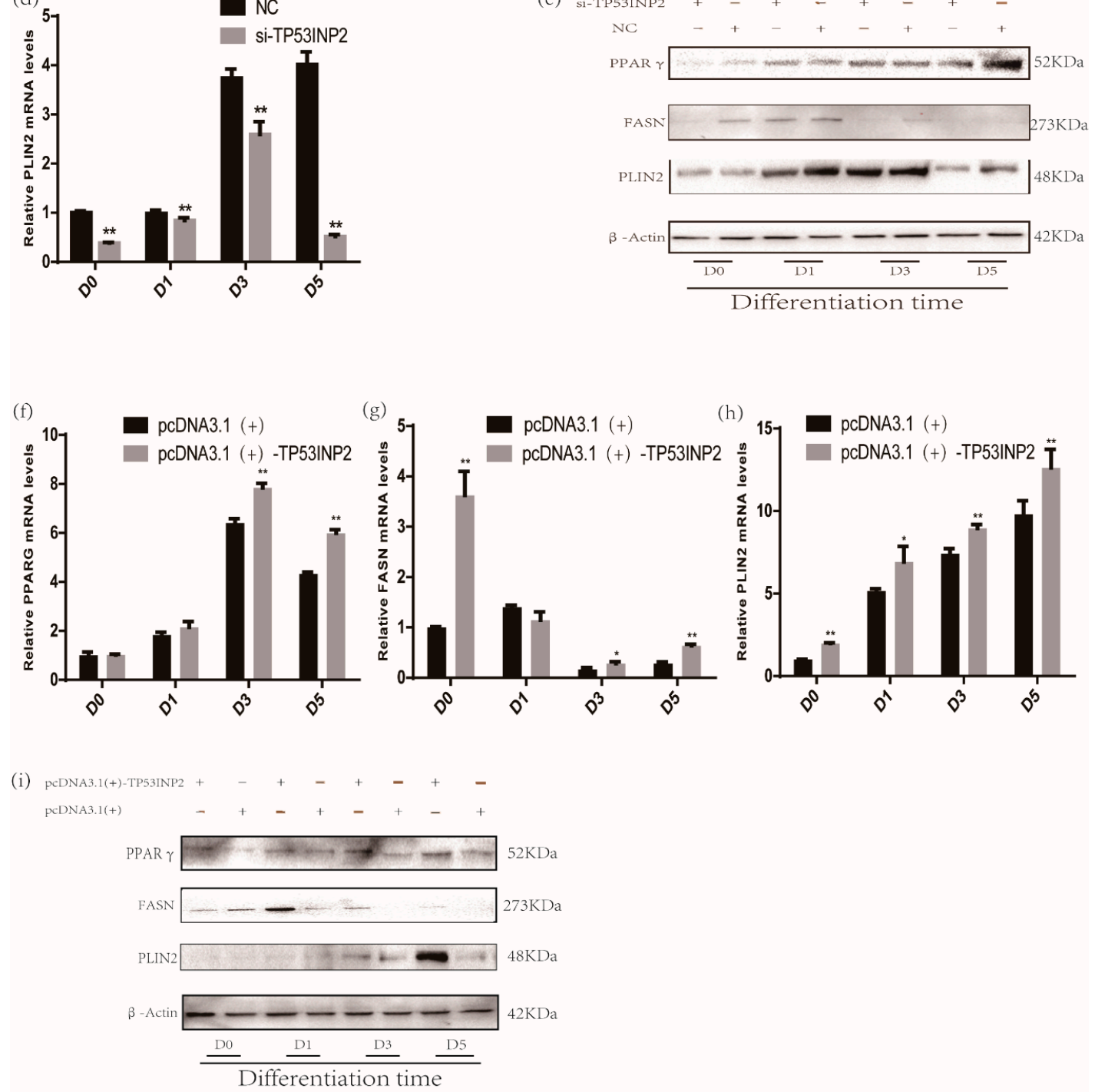

Figure 2. Effect of TP53INP2 on the differentiation of bovine adipocytes. (a) The mRNA expression pattern of TP53INP2 during differentiation was measured by RT-qPCR. (b) PPAR , (c) PLIN2 and (d) FASN mRNA levels decreased during differentiation and were determined by RT-qPCR after knocking down of TP53INP2. (e)The protein expression levels of PPAR $\gamma$, PLIN2 and FASN decreased during differentiation and were measured by Western blot after knocking down of TP53INP2. (f) PPAR $\gamma$, (g) PLIN2 and (h) FASN mRNA levels increased during differentiation and were determined by RT-qPCR after overexpressing of TP53INP2. (i) The protein expression levels of PPAR $\gamma$, PLIN2 and FASN increased during differentiation and were measured by Western blot after overexpressing of TP53INP2. Bar graphs are expressed as mean \pm S. E.M. $(n=3),{ }^{*}, p<0.05 ;{ }^{* *}, p<0.01$, compared with NC and empty vector. NC, negative control. 
(a) NC LT+DAPI
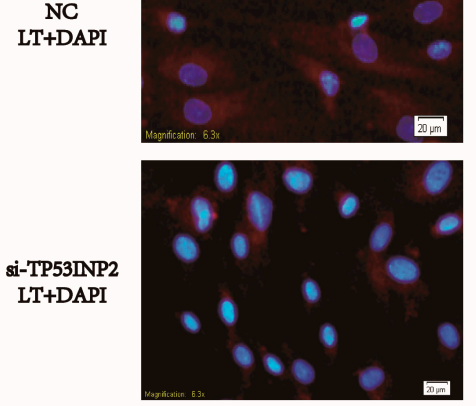

(b)

D0
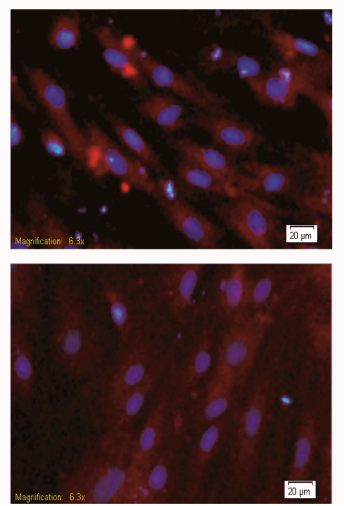
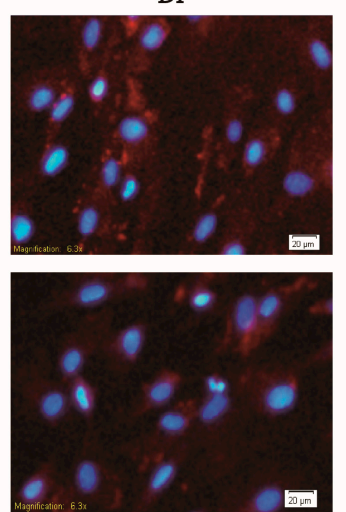

D1
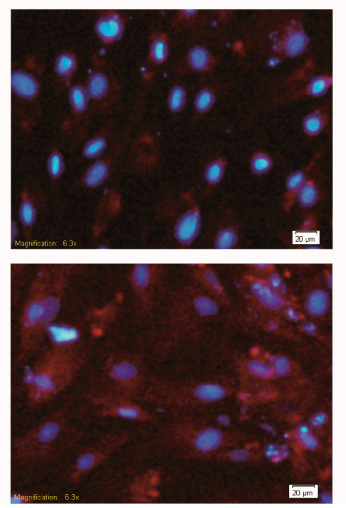
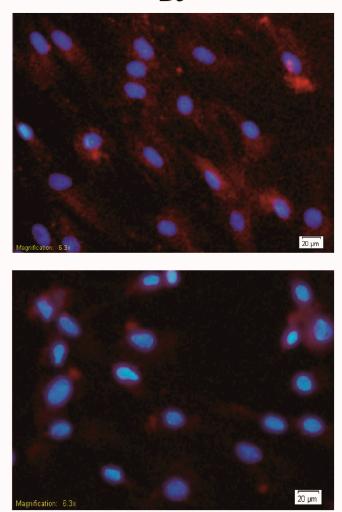

D3
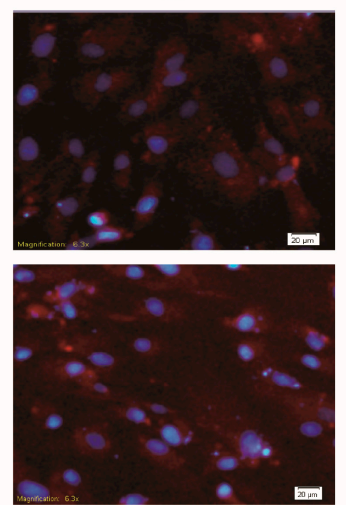
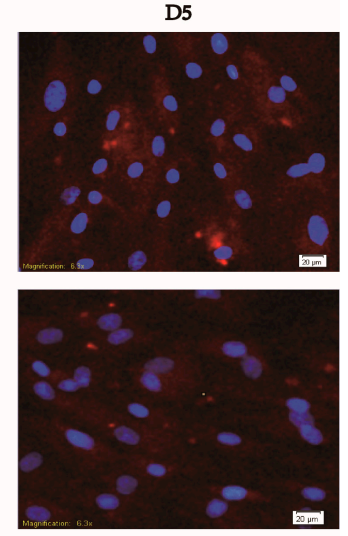

D5
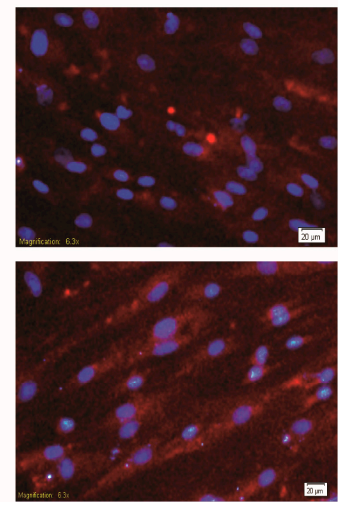

Figure 3. Lipid staining of lipid droplets in bovine adipocytes during differentiation. (a) Lipid staining of differentiated adipocytes by HCS LipidTOX ${ }^{\mathrm{TM}}$ Deep Red Neutral Lipid Stain (red) and nucleus were stained via DAPI (blue), the lipid droplets were less than the control group after knocking down of TP53INP2 $(20 \mu \mathrm{m})$. (b) Lipid staining of differentiated adipocytes via HCS LipidTOX ${ }^{\mathrm{TM}}$ Deep Red Neutral Lipid Stain (red) and nucleus were stained via DAPI (blue), the lipid droplets were more than the control group after overexpressing of TP53INP2 $(20 \mu \mathrm{m})$. Compared with NC and empty vector. NC, negative control; LT, HCS LipidTOX ${ }^{\mathrm{TM}}$ Deep Red Neutral Lipid Stain; DAPI, 4',6-diamidino-2-phenylindole.

\subsection{TP53INP2 Induces Autophagy During the Differentiation}

We also evaluated the role of TP53INP2 in autophagy during the differentiation of bovine adipocytes. In our results, the mRNA levels of ATG7 and BECN1 were gradually upregulated during differentiation, and the LC3 protein level was also upregulated. Knocking down TP53INP2 during differentiation could reduce the mRNA levels of autophagy marker genes, including ATG7 and BECN1. The protein level of LC3-II was decreased, and the protein level of p62 was increased (Figure 4a-c, Supplementary Materials, Figure S4a-b). To further confirm the role of TP53INP2 in autophagy, we observed autophagy via dansylcadaverine staining. The staining results showed that knocking down TP53INP2 significantly decreased autophagy when compared with the negative control. At the same time, when autophagy was inhibited, it could be observed that the content of the lipid droplets was also reduced (Figure 5a, Supplementary Materials, Figure S6a). The overexpression of TP53INP2 resulted in an inverse tendency, and the expression of ATG7, BECN1 and LC3-II was increased and that of p62 was decreased (Figure $4 \mathrm{~d}-\mathrm{f}$, Supplementary Materials, Figure S4c-d). Furthermore, the staining assay revealed that autophagy was induced. (Figure 5b, Supplementary Materials, Figure S6b). Overall, TP53INP2 positively regulated autophagy during the differentiation of bovine adipocytes. 


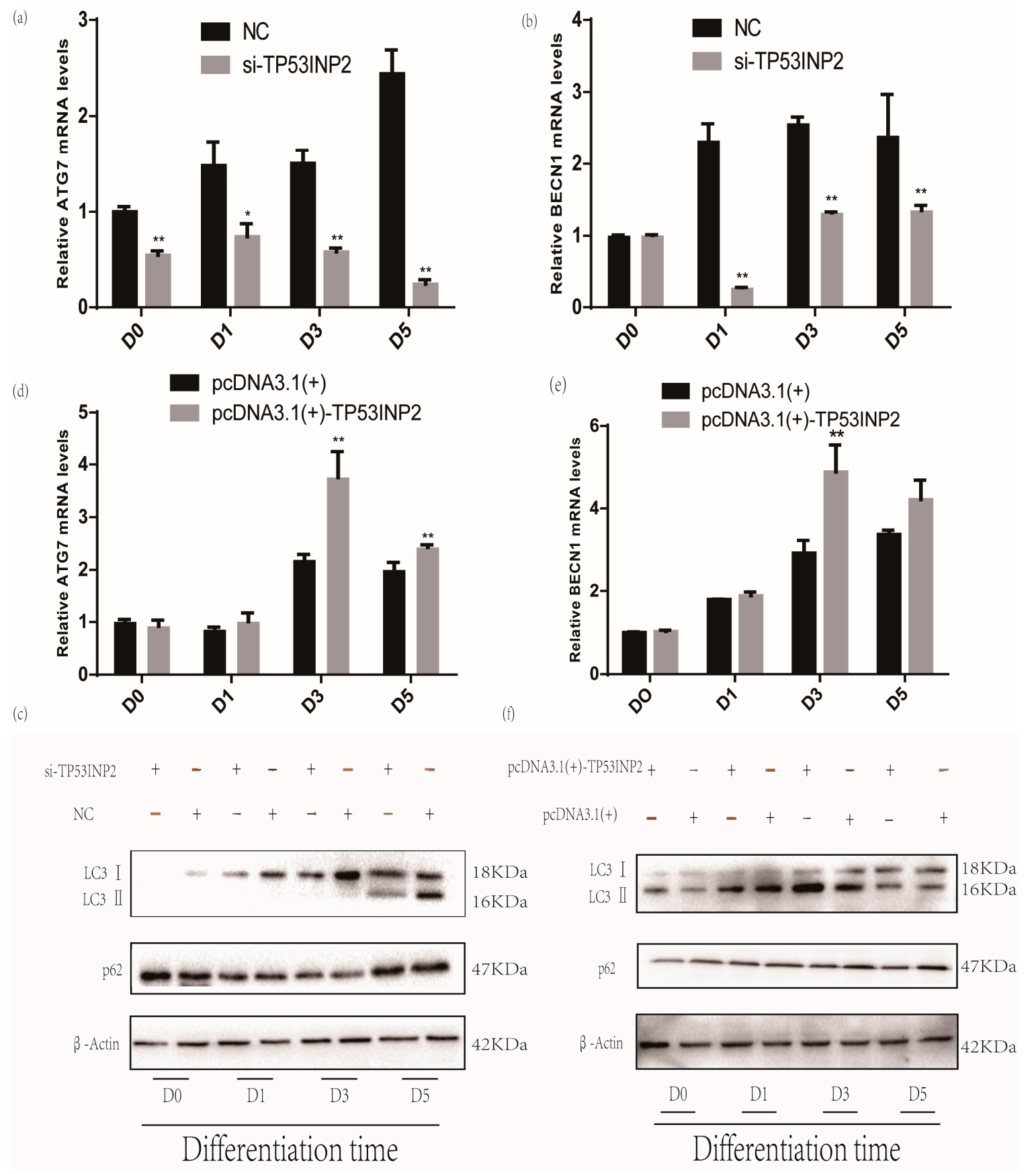

Figure 4. TP53INP2 induced autophagy. After interfering of TP53INP2, the mRNA expression of (a) ATG7 and (b) BECN1 were downregulated during adipocyte differentiation as detected by the RT-qPCR method. (c) LC3 and p62 protein levels during differentiation were evaluated by Western blot after interfering TP53INP2. After overexpressing of TP53INP2, the mRNA expression of (d) ATG7 and (e) $B E C N 1$ were upregulated during adipocyte differentiation as detected by the RT-qPCR method. (f) LC3 and p62 protein levels during differentiation were evaluated by Western blot after overexpressing of TP53INP2. Bar graphs are expressed as mean \pm S. E.M. $(n=3),{ }^{*}, p<0.05 ;{ }^{* *}, p<0.01$, compared with $\mathrm{NC}$ and empty vector. NC, negative control. 

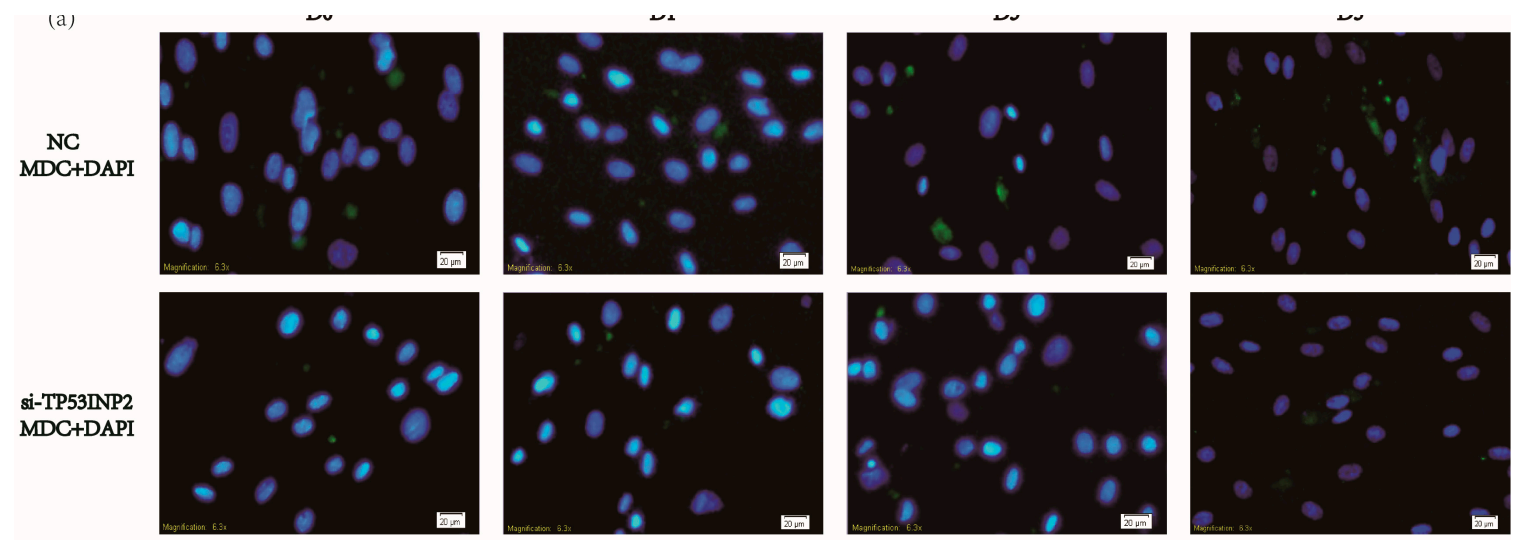

D1
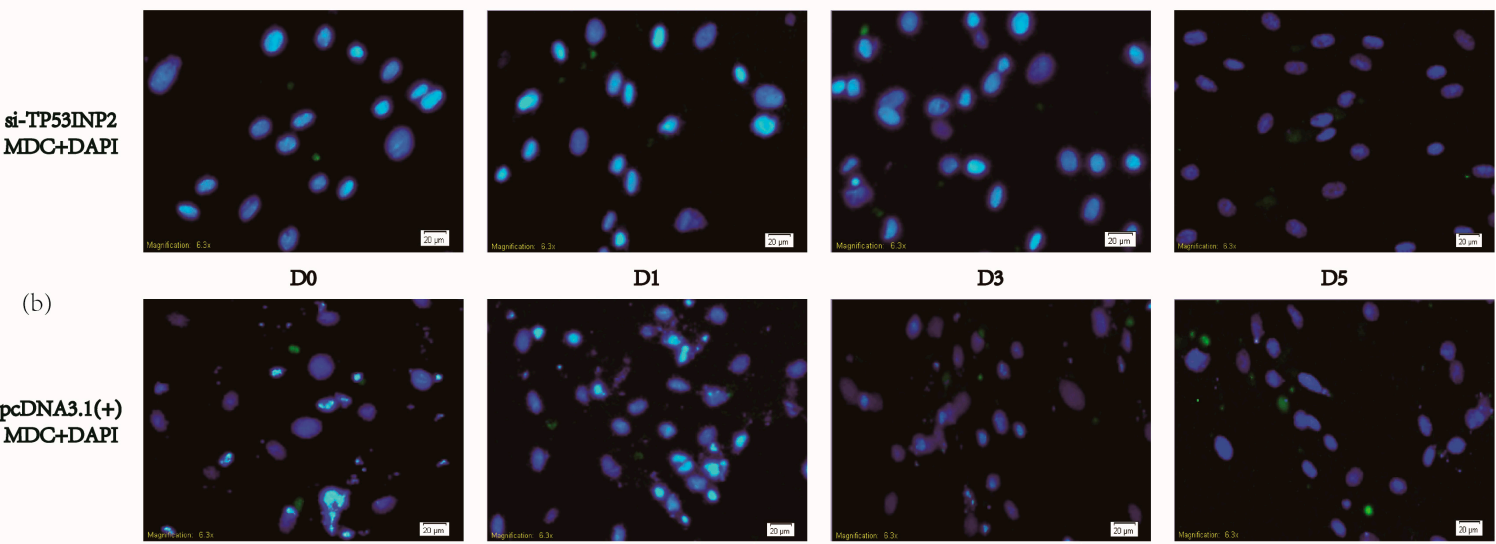

D3

D5
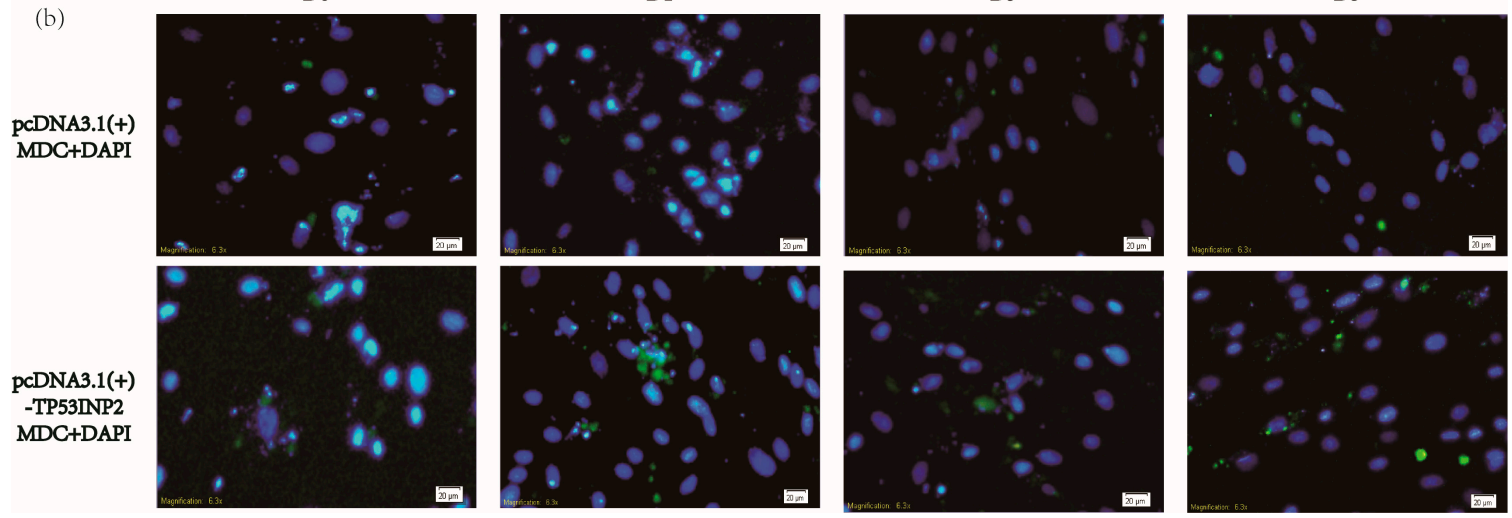

Figure 5. Dansylcadaverine staining to monitor autophagy flux in bovine adipocytes during differentiation. (a) Dansylcadaverine staining (green) used to monitor autophagy flux, the autophagy was inhibited after interfering TP53INP2 during adipocytes differentiation $(20 \mu \mathrm{m})$. (b) Dansylcadaverine staining (green) used to monitor autophagy flux the autophagy was activated after overexpressing of TP53INP2 during adipocytes differentiation $(20 \mu \mathrm{m})$. Compared with NC and empty vector. NC, negative control; DAPI, 4',6-diamidino-2-phenylindole; MDC, Dansylcadaverine.

Our experimental data demonstrated that TP53INP2 could regulate bovine adipocyte differentiation; therefore, altering the level of autophagy via changing the expression level of TP53INP2 affected the differentiation of bovine adipocytes.

\subsection{TP53INP2 Promotes the Adipocytes Differentiation Through PPAR $\gamma$ the Pathway}

According to the experimental results, we found that when the expression level of TP53INP2 was overexpressed or reduced, the protein and mRNA levels of PPAR $\gamma, F A S N$, and PLIN2 were significantly increased or decreased; however, $\operatorname{PPAR} \gamma$ is a crucial transcription factor that can regulate the expression of other genes. Therefore, we hypothesized that TP53INP2 may regulate bovine adipocyte differentiation through the PPAR $\gamma$ pathway. To explore the mechanism by which TP53INP2 regulates adipocyte differentiation, we performed a rescue experiment on the third day after the induction of differentiation. The results indicated that the overexpression of PPAR $\gamma$ induced by the PPAR $\gamma$ agonist rosiglitazone restored the reduction of lipids caused by decreasing the expression of TP53INP2 (Figure 6e, Supplementary Materials, Figure S7d) and upregulated the protein and mRNA levels of the differentiation marker PLIN2 and the protein level of FASN (Figure 6a-d, Supplementary Materials, Figure S7a-c). Hence, these results implied that TP53INP2-regulated adipocyte differentiation may be related to PPAR $\gamma$. 
(a)

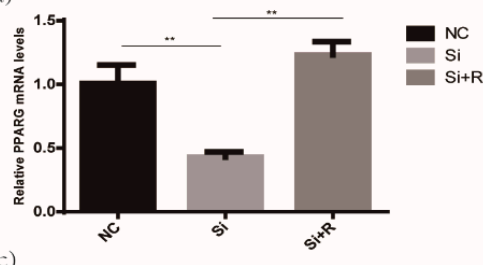

(c)

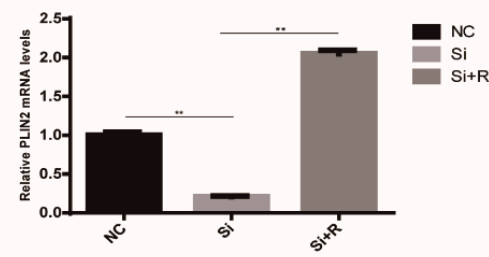

(b)

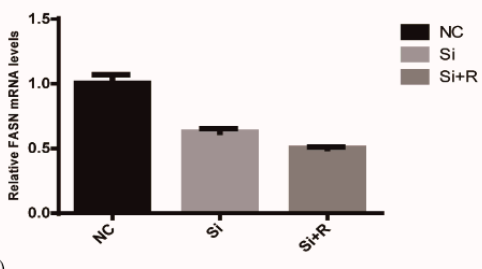

(d)

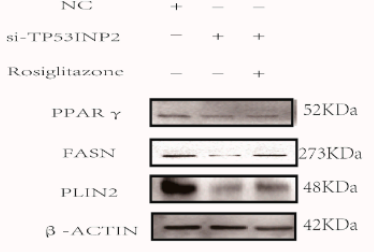

(e)

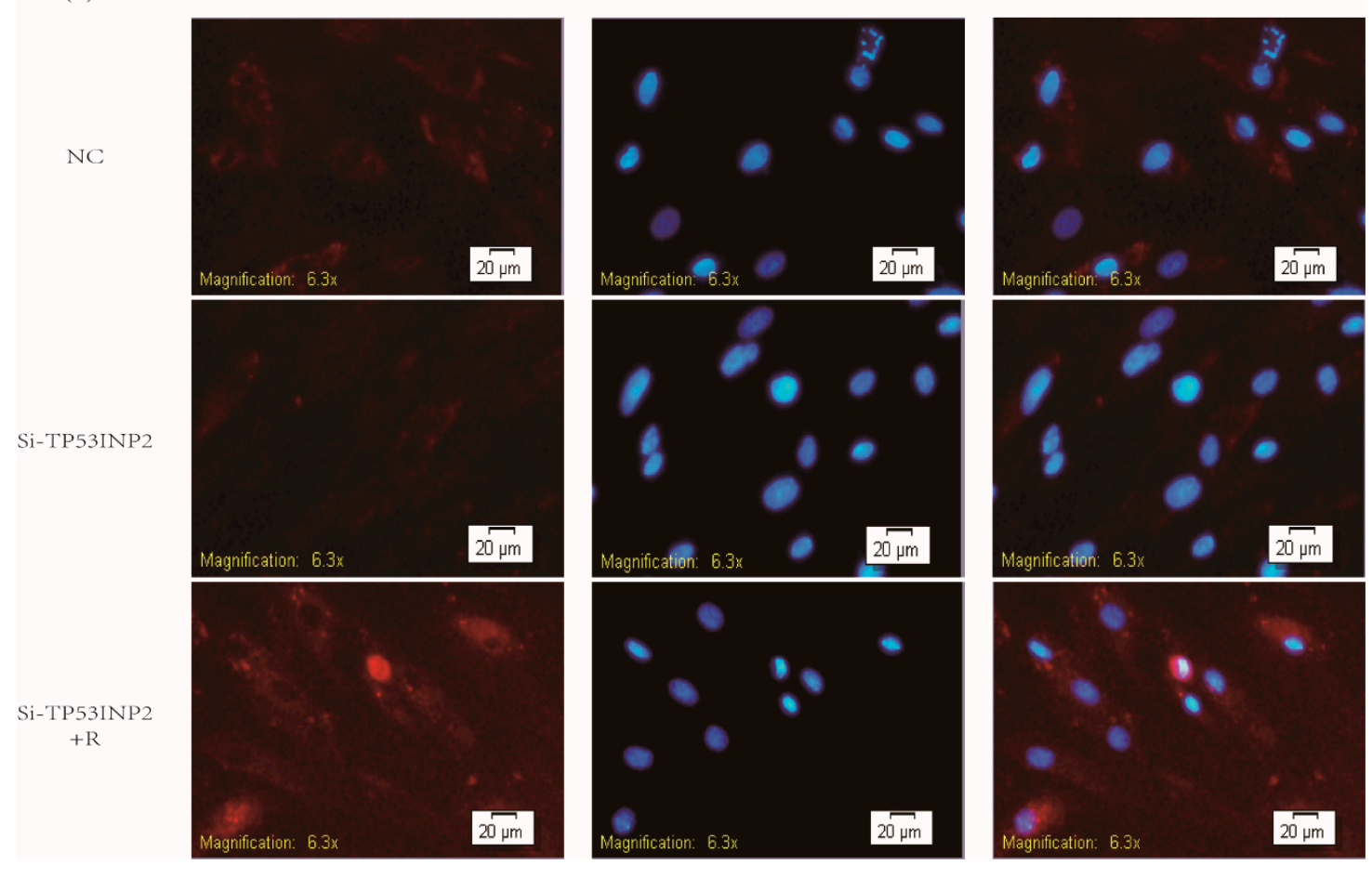

Figure 6. Activating the transcriptional activity of PPAR $\gamma$ can restore the decrease in lipid droplets and downregulation of differentiation genes caused by knocking down of TP53INP2. (a) PPAR $\gamma$, (b) PLIN2, and (c) FASN mRNA expression were evaluated via RT-qPCR, rosiglitazone upregulated the mRNA levels of PLIN2 caused by decreasing the expression of TP53INP2. (d) PPAR $\gamma$, PLIN2 and FASN protein expression were evaluated via Western blot, rosiglitazone upregulated the protein level of PLIN2 and FASN caused by decreasing the expression of TP53INP2. (e) Lipid droplets was stained via HCS LipidTOX ${ }^{\mathrm{TM}}$ Deep Red Neutral Lipid Stain (red) $(20 \mu \mathrm{m})$, rosiglitazone restored the reduction of lipids caused by decreasing the expression of TP53INP2. Transfected TP53INP2 siRNA and NC into bovine adipocytes, next induced differentiation 3 days. Bar graphs are expressed as mean \pm S.E.M. $(n=3),{ }^{* *}, p<0.01$, compared with NC. NC, negative control; DAPI, 4',6-diamidino-2-phenylindole; $\mathrm{R}$, rosiglitazone.

\section{Discussion}

According to the expression of TP53INP2, we found that the peak in mRNA expression on the second day after the induction of differentiation was significantly higher than that on the uninduced day and the fourth day after induction. Some studies have confirmed that autophagy plays an essential role in the early stage of adipocyte differentiation [30]. Therefore, we chose to examine cells transfected 
with the overexpression vector, siRNA, empty vector and NC (control) on D0 (uninduced), D1, D3, and D5 after differentiation induction. A previous study demonstrated that after knocking down TP53INP2 in 3T3-L1 cells, adipocytes became larger and contained aggregated triglycerides. In addition, the inhibition of TP53INP2 expression during 3T3-L1 preadipocyte differentiation significantly increased the expression of the differentiation markers PPAR $\gamma$ and CEBP $\alpha$. Perlipin A/B and GLUT4 were also upregulated. In contrast, the overexpression of TP53INP2 in adipocytes decreased triglyceride levels, and PPAR $\gamma$ and CEBP $\alpha$ expression were also downregulated. In conclusion, TP53INP2 is a negative regulator of 3T3-L1 preadipocyte differentiation, which also suggests that TP53INP2 participates in the regulation of adipocyte differentiation [18]. Our results indicated that the overexpression of TP53INP2 promoted bovine adipocyte differentiation through increasing the amount of lipids and upregulating PPAR $\gamma$, PLIN2, and FASN at both the mRNA and protein levels. A reduction in TP53INP2 resulted in the inverse of that observed in the overexpression group. The most important physiological function of PPAR $\gamma$ is to positively regulate adipogenesis [31]. In our study, PPAR $\gamma$ expression was gradually increased after inducing differentiation, and both the mRNA and protein levels of PPAR $\gamma$ were positively correlated with the expression of TP53INP2 during differentiation. PLIN2 is a lipid-droplet surface membrane protein that localizes to the surfaces of lipid droplets. PLIN2 promotes the formation of early lipid droplets in bovine adipocytes [32]. Our work indicated that TP53INP2 and PLIN2 are positively correlated, indicating that TP53INP2 participates in the regulation of early lipid droplet formation. FASN is a multifunctional enzyme, and its main function is to promote the synthesis of long-chain fatty acids [33]. Our research showed that FASN began to be expressed after the induction of differentiation and that TP53INP2 could significantly change the expression of FASN, which suggested that TP53INP2 is involved in lipid accumulation. Therefore, we hypothesize that the reasons for the different effects of TP53INP2 in mouse and bovine adipocytes are that (a) the TP53INP2 gene has species-specific differences in mice and cows individuals and (b) the inhibition of TP53INP2 expression in 3T3-L1 preadipocytes was not associated with decreased autophagy flux [18]; however, in our study, the suppression of TP53INP2 expression in bovine adipocytes significantly inhibited autophagy. Hence, we speculated that TP53INP2 promoted differentiation by affecting autophagy and (c) our results showed that TP53INP2 activated the transcriptional activity of PPAR $\gamma$, therefore, we hypothesized that TP53INP2 may promote bovine adipocyte differentiation through the PPAR $\gamma$ pathway. However, the specific mechanism is still unclear, and we need to further confirm this.

Some reports have demonstrated that TP53INP2 is essential for autophagy in mammalian cells [34]. It can shuttle between the nucleus and cytoplasm. When autophagy occurs, TP53INP2 relocates to the autophagosome and interacts with the autophagy-associated proteins GATE16 and LC3 [17]. In addition, it has been reported that the inhibition of TP53INP2 expression by small interfering RNA can repress autophagosome formation. Autophagy flux is very low in 3T3-L1 preadipocytes, and the knockdown of TP53INP2 during adipocyte differentiation has no effect on autophagy [18]. However, the present study demonstrated that TP53INP2 promoted autophagy in bovine adipocytes. ATG7 encodes an E1-like activating enzyme that is necessary for autophagy. A previous report revealed that ATG7 regulates adipocyte differentiation in mice [14]. BECN1 is also an autophagy marker gene. Our research showed that the mRNA expression levels of ATG7 and BECN1 gradually increased during adipocyte differentiation, and the overexpression or deficiency of TP53INP2 significantly upregulated or downregulated the ATG7 and BECN1 mRNA levels, respectively. We also measured the protein expression levels of LC3 and p62, which are two marker proteins of autophagy. Some reports have indicated that LC3 protein translation produces two forms, LC3-I and LC3-II. When autophagy is activated, LC3-I transforms into LC3-II, and the amount of LC3-II is related to the level of autophagy [35]. In our study, interference with TP53INP2 expression, which suppressed the induction of differentiation, caused LC3-I to hardly be expressed in the si-TP53INP2 group. After the induction of differentiation, LC3-I was expressed until the third day after the induction of differentiation; LC3-I conversion into LC3-II and the ratio of LC3-II to LC3-I in the si-TP53INP2 group was always lower than that in the control group during differentiation. However, after transfection of the overexpression 
vector, LC3-I began to be converted into LC3-II in undifferentiated adipocytes. As differentiation progressed, the ratio of LC3-II to LC3-I gradually increased, and the ratio in the overexpression group was always higher than that in the empty vector group. p62 can also be used to monitor autophagy flux. When autophagy occurs, p62 binds to LC3 and is efficiently degraded by autophagy [36]. In our research, due to the deficiency of TP53INP2, p62 could not be degraded. In the control group, in which differentiation was induced on the third and fifth days, p62 was almost completely degraded, and the protein expression level of p62 in the si-TP53INP2 group was also significantly lower on the third and fifth days than on the other differentiation days. After the induction of differentiation on the third day, p62 was hardly expressed in the overexpression group. The above experimental results show that TP53INP2 could regulate autophagy during the early stage of differentiation in bovine adipocytes.

Many reports have shown that autophagy could regulate the differentiation of adipocytes, especially in the early stage of adipocyte differentiation. Autophagy plays a very important role [37,38]. Specifically, by knocking out ATG7 in adipose tissue, mutant mice become very slim and have less white adipose tissue content than wild-type mice; the number of adipocytes in mutant mice are decreased, and the mitochondrial content is increased [14]. The specific knockdown of ATG7 in mouse 3T3-L1 preadipocytes led to reduced TG deposition and the downregulation of marker genes of adipocyte differentiation [39]. Similarly, the specific knockdown of ATG5, which encodes a protein necessary for autophagy in mouse MEFs, results in a decrease in normal differentiation [13]. The regulation of the differentiation of bovine adipocytes by autophagy has not been reported. In this study, the measurement of TP53INP2 mRNA expression during differentiation showed a high abundance of TP53INP2 on the second day after the induction of differentiation, and TP53INP2 activated autophagy after the induction of differentiation, which is consistent with studies that showed that autophagy played an important role in the 2nd and 3rd days of adipocyte differentiation. In addition, our experimental results proved that TP53INP2 has a significant effect on the early differentiation of bovine adipocytes. Therefore, we speculated that TP53INP2 may regulate the differentiation of bovine adipocytes by affecting autophagy. In addition to functioning as an autophagy-related protein, TP53INP2 is also an important transcription factor. A previous study found that TP53INP2 negatively regulates adipocyte differentiation in 3T3-L1 cells by altering the expression of PPAR $\gamma$ and CEBP $\alpha$ [18]. PPAR $\gamma$ is a very crucial transcription factor and is highly expressed in white and brown adipose tissue. It has also been demonstrated that PPAR $\gamma$ plays a vital role in the formation of mature adipocytes [40]. Therefore, to investigate whether TP53INP2 can regulate adipocyte differentiation through PPAR $\gamma$ in bovine adipocytes, we performed a rescue experiment with rosiglitazone, a PPAR $\gamma$ agonist [41]. The results showed that the activation of PPAR $\gamma$ activity could significantly compensate for the decrease in lipid droplets and the upregulation of PLIN2 and FASN caused by the knockdown of TP53INP2. We hypothesized that PPAR $\gamma$ may contribute to the function of TP53INP2 in bovine adipocytes.

Several studies have demonstrated that mTOR regulates the synthesis of proteins and leptin in adipocytes. It is also documented that mTOR regulates the activity of PPAR $\gamma$, so mTOR is critical for the initiation of adipocyte differentiation and the maintenance of lipid synthesis [42]. The mTOR pathway has also been reported to have important regulatory effects on autophagy [43]. Thus, further research should focus on the upstream signaling pathways associated with autophagy and differentiation to help improve the understanding of the mechanisms underlying the regulation of adipocyte differentiation by autophagy.

In summary, we found that a novel, important autophagy protein could regulate differentiation in bovine adipocytes. TP53INP2 induced autophagy and PPAR $\gamma$ expression, which may be a key factor in adipocyte differentiation.

\section{Conclusions}

In conclusion, our study found an autophagy-related protein that could promote differentiation in bovine adipocytes; in addition, it could regulate autophagy during the early stage of differentiation in bovine adipocytes. Therefore, we hypothesized that TP53INP2 regulated the differentiation of bovine 
adipocytes by altering the level of autophagy. Finally, we hypothesized that PPAR $\gamma$ may contribute to the function of TP53INP2 in bovine adipocytes via the rescue experiment.

Supplementary Materials: The following are available online at http://www.mdpi.com/2076-2615/9/12/1060/s1, Figure S1: Protein quantitative analysis of overexpressing and interference efficiency. Figure S2: Detection of overexpression and interference efficiency of mRNA levels in different stages. Figure S3: Quantified the adipocytes differentiation-related protein levels. Figure S4: Quantified the autophagy-related protein levels. Figure S5: Quantification of the LipidTOX ${ }^{\mathrm{TM}}$ stain images. Figure S6: Quantification of the MDC stain images. Figure S7: Quantification of the rescue experiment results.

Author Contributions: Conceptualization, W.Z. and P.L.; methodology, W.Z.; software, S.W.; validation, L.W., X.M. and X.S.; formal analysis, W.Z.; investigation, W.Z.; resources, Y.W.; data curation, W.Z.; writing-original draft preparation, W.Z.; writing—review and editing, P.L. and G.C.; visualization, G.C.; supervision, L.Z.; funding acquisition, L.Z.

Funding: This research was funded by the National Key Research and Development Program of China, grant number 2018YFD0501700, the National Key Technology Support Program, grant number 2015BAD03B04, the National Beef and Yak Industrial Technology System, grant number CARS-37, the Agricultural Science and Technology Innovation and Transformation Project of Shaanxi Province, grant number NYKJ-2018-LY09 and the Technical Innovation Engineering Project of Shaanxi Province, grant number 2016 KTCL02-15.

Acknowledgments: We thank the staff and technicians for collecting samples.

Conflicts of Interest: The authors declare no conflict of interests.

\section{References}

1. Eskelinen, E.L.; Saftig, P. Autophagy: A lysosomal degradation pathway with a central role in health and disease. Biochim. Et Biophys. Acta Mol. Cell Res. 2009, 1793, 664-673. [CrossRef]

2. Kim, K.H.; Lee, M.S. Autophagy-A key player in cellular and body metabolism. Nat. Rev. Endocrinol. 2014, 10, 322. [CrossRef]

3. Mizushima, N. Autophagy: Process and function. Genes Dev. 2007, 21, 2861-2873. [CrossRef]

4. Masclaux-Daubresse, C.; Chen, Q.; Have, M. Regulation of nutrient recycling via autophagy. Curr. Opin. Plant Biol. 2017, 39, 8-17. [CrossRef]

5. Rubinsztein, D.C.; DiFiglia, M.; Heintz, N.; Nixon, R.A.; Qin, Z.H.; Ravikumar, B.; Stefanis, L.; Tolkovsky, A. Autophagy and its possible roles in nervous system diseases, damage and repair. Autophagy 2005, 1, 11-22. [CrossRef]

6. Chang, Y.Y.; Neufeld, T.P. An ATG1/ATG13 complex with multiple roles in TOR-mediated autophagy regulation. Mol. Biol. Cell 2009, 20, 2004. [CrossRef]

7. Yu, L.; McPhee, C.K.; Zheng, L.; Mardones, G.A.; Rong, Y.; Peng, J.; Mi, N.; Zhao, Y.; Liu, Z.; Wan, F.; et al. Termination of autophagy and reformation of lysosomes regulated by mTOR. Nature 2010, 465, 942-946. [CrossRef]

8. Goldman, S.; Zhang, Y.; Jin, S. Autophagy and adipogenesis: Implications in obesity and type II diabetes. Autophagy 2010, 6, 179-181. [CrossRef]

9. Kovsan, J.; Blüher, M.; Tarnovscki, T.; Klöting, N.; Kirshtein, B.; Madar, L.; Shai, I.; Golan, R.; Harman-Boehm, I.; Schön, M.R.; et al. Altered autophagy in human adipose tissues in obesity. J. Clin. Endocrinol. Metab. 2011, 96, E268-E277. [CrossRef]

10. Tao, Z.; Liu, L.; Zheng, L.D.; Cheng, Z. Autophagy in Adipocyte Differentiation. Methods Mol. Biol. 2017, $1854,45-53$.

11. Chechi, K.; Carpentier, A.C.; Richard, D. Understanding the brown adipocyte as a contributor to energy homeostasis. Trends Endocrinol. Metab. 2013, 24, 408-420. [CrossRef]

12. Wang, S.; Peng, D. Regulation of adipocyte autophagy_-The potential anti-obesity mechanism of high density lipoprotein and ApolipoproteinA-I. Lipids Heal. Dis. 2012, 11, 131. [CrossRef]

13. Baerga, R.; Zhang, Y.; Chen, P.H.; Goldman, S.; Jin, S.V. Targeted deletion of autophagy-related 5 (ATG5) impairs adipogenesis in a cellular model and in mice. Autophagy 2009, 5, 1118-1130. [CrossRef]

14. Zhang, Y.; Goldman, S.; Baerga, R.; Zhao, Y.; Komatsu, M.; Jin, S. Adipose-specific deletion of autophagy-related gene 7 (ATG7) in mice reveals a role in adipogenesis. Autophagy 2009, 106, 19860-19865. [CrossRef] 
15. Hu, Y.; Li, X.; Xue, W.; Pang, J.; Meng, Y.; Shen, Y.; Xu, Q. TP53INP2-related basal autophagy is involved in the growth and malignant progression in human liposarcoma cells. Biomed. Pharm. 2017, 88, 562-568. [CrossRef]

16. Nowak, J.; Archange, C.; Tardivel-Lacombe, J.; Pontarotti, P.; Pébusque, M.J.; Vaccaro, M.I.; Velasco, G.; Dagorn, J.C.; Iovanna, J.L. The TP53INP2 protein is required for autophagy in mammalian cells. Mol. Biol. Cell 2009, 20, 870-881. [CrossRef]

17. Fromm-Dornieden, C.; Lytovchenko, O.; von der Heyde, S.; Behnke, N.; Hogl, S.; Berghoff, J.; Köpper, F.; Opitz, L.; Renne, U.; Hoeflich, A.; et al. Extrinsic and intrinsic regulation of DOR/TP53INP2 expression in mice: Effects of dietary fat content, tissue type and sex in adipose and muscle tissues. Nutr. Metab. 2012, 9, 86. [CrossRef]

18. Romero, M.; Sabate-Perez, A.; Francis, V.A.; Castrillon-Rodriguez, I.; Diaz-Ramos, A.; Sanchez-Feutrie, M.; Durán, X.; Palacín, M.; Moreno-Navarrete, J.M.; Gustafson, B.; et al. TP53INP2 regulates adiposity by activating $\beta$-catenin through autophagy-dependent sequestration of GSK3 $\beta$. Nat. Cell Biol. 2018, 20, 443-454. [CrossRef]

19. Peirce, V.; Carobbio, S.; Vidal-Puig, A. The different shades of fat. Nature 2014, 510, 76-83. [CrossRef]

20. Rosen, E.D.; Spiegelman, B.M. Adipocytes as regulators of energy balance and glucose homeostasis. Nature 2006, 444, 847-853. [CrossRef]

21. Rosen, E.D.; Spiegelman, B.M. What we talk about when we talk about fat. Cell 2014, 156, 20-44. [CrossRef]

22. Michalakis, K.; Mintziori, G.; Kaprara, A.; Tarlatzis, B.C.; Goulis, D.G. The complex interaction between obesity, metabolic syndrome and reproductive axis: A narrative review. Metabolism 2013, 62, 457-478. [CrossRef]

23. Ottaviani, E.; Malagoli, D.; Franceschi, C. The evolution of the adipose tissue: A neglected enigma. Gen. Comp. Endocrinol. 2011, 174, 1-4. [CrossRef]

24. Gesta, S.; Tseng, Y.H.; Kahn, C.R. Developmental origin of fat: Tracking obesity to its source. Cell 2007, 131, 242-256. [CrossRef]

25. Wang, Q.A.; Tao, C.; Gupta, R.K.; Scherer, P.E. Tracking adipogenesis during white adipose tissue development, expansion and regeneration. Nat. Med. 2013, 19, 1338-1344. [CrossRef]

26. Garin-Shkolnik, T.; Rudich, A.; Hotamisligil, G.S.; Rubinstein, M. FABP4 attenuates PPAR $\gamma$ and adipogenesis and is inversely correlated with PPAR $\gamma$ in adipose tissues. Diabetes 2014, 63, 900-911. [CrossRef]

27. Mueller, E.; Drori, S.; Aiyer, A.; Yie, J.; Sarraf, P.; Chen, H.; Hauser, S.; Rosen, E.D.; Ge, K.; Roeder, R.G.; et al. Genetic analysis of adipogenesis through peroxisome proliferator-activated receptor $\gamma$ isoforms. J. Biol. Chem. 2002, 277, 41925-41930. [CrossRef]

28. Spiegelman, B.M. C/EBP $\alpha$ induces adipogenesis through PPAR $\gamma$ : A unified pathway. Genes Dev. 2002, 16, 2226.

29. Liu, S.; Sun, G.; Yuan, B.; Zhang, L.; Gao, Y.; Jiang, H.; Dai, L.; Zhang, J. miR-375 negatively regulates porcine preadipocyte differentiation by targeting BMPR2. FEBS Lett. 2016, 590, 1417-1427. [CrossRef]

30. Guo, L.; Huang, J.X.; Liu, Y.; Li, X.; Zhou, S.R.; Qian, S.W.; Liu, Y.; Zhu, H.; Huang, H.Y.; Dang, Y.J.; et al. Transactivation of Atg $4 \mathrm{~b}$ by C/EBP $\beta$ promotes autophagy to facilitate adipogenesis. Mol. Cell. Biol. 2013, 33, 3180-3190. [CrossRef]

31. Takada, I.; Kouzmenko, A.P.; Kato, S. Wnt and PPAR $\gamma$ signaling in osteoblastogenesis and adipogenesis. Nat. Rev. Rheumatol. 2009, 5, 442-447. [CrossRef]

32. Li, P.; Wang, Y.; Zhang, L.; Ning, Y.; Zan, L. The Expression Pattern of PLIN2 in Differentiated Adipocytes from Qinchuan Cattle Analysis of Its Protein Structure and Interaction with CGI-58. Int. J. Mol. Sci. 2018, 19, 1336. [CrossRef]

33. Jayakumar, A.; Huang, W.Y.; Raetz, B.; Chirala, S.S.; Wakil, S.J. Cloning and expression of the multifunctional human fatty acid synthase and its subdomains in Escherichia coli. Proc. Natl. Acad. Sci. USA 1996, 93, 14509-14514. [CrossRef]

34. Mauvezin, C.; Orpinell, M.; Francis, V.A.; Mansilla, F.; Duran, J.; Ribas, V.; Palacín, M.; Boya, P.; Teleman, A.A.; Zorzano, A. The nuclear cofactor DOR regulates autophagy in mammalian and Drosophila cells. Embo Rep. 2010, 11, 37-44. [CrossRef]

35. Kabeya, Y.; Mizushima, N.; Ueno, T.; Yamamoto, A.; Kirisako, T.; Noda, T.; Kominami, E.; Ohsumi, Y.; Yoshimori, T. LC3, a mammalian homologue of yeast Apg8p, is localized in autophagosome membranes after processing. Embo J. 2000, 19, 5720-5728. [CrossRef] 
36. Ichimura, Y.; Kumanomidou, T.; Sou, Y.S.; Mizushima, T.; Ezaki, J.; Ueno, T.; Kominami, E.; Yamane, T.; Tanaka, K.; Komatsu, M. Structural basis for sorting mechanism of p62 in selective autophagy. J. Biol. Chem. 2008, 283, 22847-22857. [CrossRef]

37. Jansen, H.J.; van Essen, P.; Koenen, T.; Joosten, L.A.B.; Netea, M.G.; Tack, C.J.; Stienstra, R. Autophagy activity is up-regulated in adipose tissue of obese individuals and modulates proinflammatory cytokine expression. Endocrinology 2012, 153, 5866-5874. [CrossRef]

38. Nuñez, C.E.; Rodrigues, V.S.; Gomes, F.S.; de Moura, R.F.; Victorio, S.C.; Bombassaro, B.; Chaim, E.A.; Pareja, J.C.; Geloneze, B.; Velloso, L.A.; et al. Defective regulation of adipose tissue autophagy in obesity. Int. J. Obes. (Lond.) 2013, 37, 1473-1480. [CrossRef]

39. Singh, R.; Xiang, Y.Y. Autophagy regulates adipose mass and differentiation in mice. J. Clin. Investig. 2009, 119, 3329-3339. [CrossRef]

40. He, W.; Barak, Y.; Hevener, A.; Olson, P.; Liao, D.; Le, J.; Nelson, M.; Ong, E.; Olefsky, J.M.; Evans, R.M. Adipose-specific peroxisome proliferator-activated receptor $\gamma$ knockout causes insulin resistance in fat and liver but not in muscle. Proc. Natl. Acad. Sci. USA 2003, 100, 15712-15717. [CrossRef]

41. Fayyad, A.M.; Khan, A.A.; Abdallah, S.H.; Alomran, S.S.; Bajou, K.; Khattak, M.N.K. Rosiglitazone Enhances Browning Adipocytes in Association with MAPK and PI3-K Pathways During the Differentiation of Telomerase-Transformed Mesenchymal Stromal Cells into Adipocytes. Int. J. Mol. Sci. 2019, 20, 1618. [CrossRef]

42. Morrison, R.F.; Farmer, S.R. Hormonal signaling and transcriptional control of adipocyte differentiation. J. Nutr. 2000, 130, 3116S. [CrossRef]

43. Pan, S.T.; Qin, Y.; Zhou, Z.W.; He, Z.X.; Zhang, X.; Yang, T.; Yang, Y.X.; Wang, D.; Qiu, J.X.; Zhou, S.F. Plumbagin induces G2/M arrest, apoptosis, and autophagy via p38 MAPK- and PI3K/Akt/mTOR-mediated pathways in human tongue squamous cell carcinoma cells. Drug Des. Dev. Ther. 2015, 9, 1601-1626.

(C) 2019 by the authors. Licensee MDPI, Basel, Switzerland. This article is an open access article distributed under the terms and conditions of the Creative Commons Attribution (CC BY) license (http://creativecommons.org/licenses/by/4.0/). 